\title{
Changes in cerebrospinal fluid flow assessed using intraoperative MRI during posterior fossa decompression for Chiari malformation
}

\author{
Aaron E. Bond, MD, PhD, John A. Jane Sr., MD, PhD, Kenneth C. Liu, MD, \\ and Edward H. Oldfield, MD
}

Department of Neurosurgery, University of Virginia Health Science Center, Charlottesville, Virginia

OBJECT The authors completed a prospective, institutional review board-approved study using intraoperative MRI (iMRI) in patients undergoing posterior fossa decompression (PFD) for Chiari I malformation. The purpose of the study was to examine the utility of iMRI in determining when an adequate decompression had been performed.

METHODS Patients with symptomatic Chiari I malformations with imaging findings of obstruction of the CSF space at the foramen magnum, with or without syringomyelia, were considered candidates for surgery. All patients underwent complete T1, T2, and cine MRI studies in the supine position preoperatively as a baseline. After the patient was placed prone with the neck flexed in position for surgery, iMRI was performed. The patient then underwent a bone decompression of the foramen magnum and arch of $\mathrm{C}-1$, and the MRI was repeated. If obstruction was still present, then in a stepwise fashion the patient underwent dural splitting, duraplasty, and coagulation of the tonsils, with an iMRI study performed after each step guiding the decision to proceed further.

RESULTS Eighteen patients underwent PFD for Chiari I malformations between November 2011 and February 2013; 15 prone preincision iMRIs were performed. Fourteen of these patients (93\%) demonstrated significant improvement of CSF flow through the foramen magnum dorsal to the tonsils with positioning only. This improvement was so notable that changes in CSF flow as a result of the bone decompression were difficult to discern.

CONCLUSIONS The authors observed significant CSF flow changes when simply positioning the patient for surgery. These results put into question intraoperative flow assessments that suggest adequate decompression by PFD, whether by iMRI or intraoperative ultrasound. The use of intraoperative imaging during PFD for Chiari I malformation, whether by ultrasound or iMRI, is limited by CSF flow dynamics across the foramen magnum that change significantly when the patient is positioned for surgery.

http://thejns.org/doi/abs/10.3171/2015.1.JNS132712

KEY WORDS Chiari malformation; intraoperative imaging; CSF flow; posterior fossa decompression; hydrocephalus

A CHIARI I malformation of the inferior portion of the cerebellum causes symptoms, and occasionally injury to the spinal cord, by impaction of the cerebellar tonsils in the foramen magnum, obstructing the free, pulsatile movement of CSF between the posterior fossa and the subarachnoid space of the upper cervical region. ${ }^{6,13}$ The goal of surgery is simple: surgical decompression of the craniocervical junction is performed to provide the space necessary to decompress the cerebellar tonsils and permit the CSF to flow freely between the posterior fossa and the upper portion of the spinal subarachnoid space. ${ }^{6,13}$

However, for a successful operation different degrees of surgery are required in individual patients. Some patients require only removal of the bone along the posterior rim of the foramen magnum and removal of the neural arch of $\mathrm{C}-1$. On the other hand, some patients require additional surgery to open the dura mater, and in some it is needed to open the arachnoid and explore the subarachnoid space. Patients whose surgery includes opening the dura are more likely to have the disorder successfully addressed by the surgery, although they have greater risks of complications associated with the surgery (CSF leak, pseudomeningocele, and requirement for additional surgery to address these complications). ${ }^{3,11}$ In contrast, although the least

ABBREVIATIONS $\mathrm{IMRI}=$ intraoperative MRI; PFD = posterior fossa decompression; PFDD = PFD and duraplasty.

SUBMITTED December 10, 2013. ACCEPTED January 5, 2015.

INCLUDE WHEN CITING Published online February 20, 2015; DOI: 10.3171/2015.1.JNS132712.

DISCLOSURE The authors report no conflict of interest concerning the materials or methods used in this study or the findings specified in this paper. 
amount of surgery is less likely to be associated with complications, it is also less likely to accomplish the goals of the procedure (5\%-20\% of patients do not respond), and additional surgery is required later. ${ }^{3,14}$ Durham and FjeldOlenec performed a meta-analysis in a pediatric population demonstrating that patients with posterior fossa decompression (PFD) alone had a lower likelihood of syrinx resolution than patients with PFD and duraplasty (PFDD) (56\% vs $87 \%$ ). However, they noted that patients who underwent duraplasty had a higher rate of complications (22\% vs $3 \%)^{2}$

In another study, pediatric patients undergoing PFDD required increased health care services compared with patients who underwent PFD alone. Patients in whom PFDD was performed were in the operating room 74 minutes longer than those receiving a PFD (201 \pm 34 minutes compared with $127 \pm 25$ minutes; $p=0.0001$ ), a 59\% increase..$^{11}$ Mutchnick et al. also found that morbidity was increased in the patients with PFDD; patients who underwent PFDD used low-grade narcotics, intravenous narcotics, muscle relaxants, and antiemetic medications at greater rates and for longer intervals than patients with PFD. Patients who underwent PFDD stayed in the hospital longer (4 vs 2.7 days, $\mathrm{p}=0.0001$ ), and the average cost per patient undergoing PFDD was almost 2-fold greater than for patients treated with PFD. ${ }^{11}$

Thus, as surgical therapy has evolved in the MRI era, an era in which the outcome of surgery is easier to assess and can be assessed with higher resolution, it has become apparent that simply performing the bone decompression alone, or combining the bone decompression with superficially opening the dura (partial thickness) or removing the outer layer of dura is successful in most patients. The arguments for using this approach as the initial procedure are that it reduces the morbidity of the procedure and it is usually successful, and these features outweigh the disadvantages of knowing that further surgery to open the dura will be required in 10\%-20\% of patients treated in this fashion. ${ }^{3,14}$ On the other hand, those favoring PFDD discuss the value of having the capacity to visually assess the subarachnoid space to examine for a subarachnoid abnormality (arachnoiditis, dural or arachnoid band, arachnoid cyst) after opening the dura, whether the arachnoid is left intact or not, and argue that the consistency of success and a single operation outweighs the disadvantages associated with the greater incidence of complications and additional surgery later.

Ideally there would be a method of determining during the operation the least amount of surgery that each individual patient requires to open the subarachnoid space at the foramen magnum. That is, it would be valuable if it could be determined during surgery if removal of bone alone, removal of bone combined with a partial thickness opening of the dura, or bone removal and opening the dura, but not the arachnoid, is sufficient in individual patients, so that the surgery could stop at the stage with the least intervention that is likely to be successful. Intraoperative ultrasound has been used for this, to examine the distance between the inner layer of dura and the posterior edge of the cerebellar tonsils and to assess the pulsatility of the cerebellar tonsils and the spinal cord surrounding a syrinx, to see if bone decompression or partial-thickness dural incision would provide the extra space needed., ${ }^{73,14}$ Although its value has not been established, intraoperative MRI (iMRI), which permits anatomical imaging and imaging of CSF and tissue movement, should also be valuable for determining during surgery when the procedure has provided 1) additional space between the posterior margin of the cerebellar tonsils and the inner layer of dura, 2) additional distance between the ventral surface of the brainstem and the inner layer of the dura anterior to the foramen magnum, and 3) sufficient space at the foramen magnum for pulsatile movement of CSF in the subarachnoid space at the level of the foramen magnum, by using phase-contrast MRI. The purpose of our study was to assess the utility of iMRI in establishing the stage at which success has been achieved during surgical treatment of patients with Chiari I malformation.

\section{Methods}

Following institutional review board approval, patients with symptomatic Chiari I malformations, with or without syringomyelia, consented to be included in the study. All patients underwent preoperative assessment, which included history, physical examination, conventional baseline MRI studies of the brain and spinal cord, and cine MRI at the craniovertebral junction in the supine position. The results were used as a basis for recommending surgery, and for comparison with iMRI studies obtained during the operation.

On the day of surgery, the patient was brought to the iMRI suite and intubated. The head was placed in a 3-pin Mayfield headholder, the patient was rotated prone, and the neck was gently flexed to ensure that 1-2 fingerbreadths of space existed between the chin and chest. With the patient in the operative position, iMRI, including anatomical imaging with T1- and T2-weighted sequences as well as cine imaging centered on the foramen magnum, was performed.

Following muscular dissection and exposure, the bone decompression was completed. In all patients, the arch of $\mathrm{C}-1$ was removed. The bone PFD was $2.5 \mathrm{~cm}$ wide by 2 $\mathrm{cm}$ high from the lip of the foramen magnum, and $2 \mathrm{~cm}$ of the arch of C-1 was removed. The fibrous band between $\mathrm{C}-1$ and the foramen magnum was then sharply dissected free, using care not to violate the dura. The patient was then covered in a series of sterile drapes, which were later removed, and iMRI was performed. A standard series of T1-weighted, T2-weighted, and phase-contrast cine studies were obtained. The results were then reviewed by the attending surgeon and by the radiologist. If improvement in CSF flow was noted and there was no obvious significant obstruction of the dorsal CSF space at the level of the foramen magnum, further decompression was not performed and the operation was completed after closure. It should be noted that the assessment of the flow was qualitative and used anatomical MRI and phase-contrast imaging without direct measurement of flow velocities.

In the event that there was still significant obstruction noted on the iMRI or no obvious change from the preoperative scan, surgery proceeded to dural splitting and another iMRI was performed. The same criteria were 
used to determine whether to proceed to duraplasty or to coagulation of the tonsils in a stepwise fashion. If a patient proceeded through additional stages of surgery the iMRI assessment was repeated using the same methods. In the beginning of the study each iMRI session added approximately 1.5 hours to the surgery. Toward the end of the study, as we became more experienced, each iMRI added 45 minutes to the surgery. The patients were counseled during the consenting process that the iMRI added significant time to the surgery as well as the subsequent risk of facial swelling and pulmonary complications of longer anesthesia in the prone position.

\section{Results}

Summaries of the patient age, sex, prior surgery status, MRI characteristics preoperatively and postoperatively, surgery performed, follow-up times, and outcomes are shown in Table 1.

\section{Patient Demographic Data and Presenting Symptoms}

Eighteen patients were included in this study. Eightynine percent of patients were female, and the mean age was 40.4 years with a minimum age of 18.5 years, a maximum age of 73.9 years, and a median age of 40.7 years. Although the protocol allowed the inclusion of pediatric patients, none presented for surgery in the time period of the study. The body mass index of the patients varied from a minimum of 18 to a maximum of 39.7, with a mean of
27.3 and a median of 25.6. Twenty-two percent of patients had had a prior PFD (1 bone decompression only, $2 \mathrm{du}-$ ral openings, and 1 duraplasty). The primary presenting symptoms were suboccipital headaches (67\%). Paresthesias were present in $28 \%$ of patients. Other symptoms included neck pain (17\%), ataxia (11\%), and other miscellaneous symptoms (arm pain, vertigo, arm/hand weakness, tinnitus, and fatigue).

\section{Imaging Findings}

The average tonsil descent below the level of the foramen magnum was $12.9 \mathrm{~mm}$, with a minimum of $7 \mathrm{~mm}$ and a maximum of $25 \mathrm{~mm}$. The ventral and dorsal CSF space was measured at the level of the foramen magnum between the ventral aspect of the spinal cord and the dorsal aspect of the tonsils to the inner surface of the ventral and dorsal dura, respectively, as seen on T2-weighted sagittal imaging. The range of ventral CSF noted preoperatively was $0-5.6 \mathrm{~mm}$, with a mean of $1.6 \mathrm{~mm}$ and a median of $1.1 \mathrm{~mm}$. The range of the dorsal CSF space was $0-2 \mathrm{~mm}$, with a mean of $0.3 \mathrm{~mm}$ and a median of $0 \mathrm{~mm}$.

Thirteen patients $(72 \%)$ demonstrated a cervicomedullary hump, 6 (33\%) had syringomyelia, and $13(72 \%)$ had pointed tonsils. All patients had demonstration of obstructed dorsal CSF flow on phase-contrast MRI studies.

\section{Effect of Positioning on MRI Results}

Of the 18 patients who underwent PFD for Chiari I

TABLE 1. Summary of MRI results during surgery in 18 patients with Chiari I malformations

\begin{tabular}{|c|c|c|c|c|c|c|}
\hline $\begin{array}{l}\text { Case } \\
\text { No. }\end{array}$ & $\begin{array}{c}\text { Preop } \\
\text { Prone } \\
\text { MRI }\end{array}$ & $\begin{array}{c}\text { Ventral CSF } \\
\text { Space, Supine } \\
\text { Preop MRI (mm)* }\end{array}$ & $\begin{array}{l}\text { Change in Ventral } \\
\text { CSF Space, Prone } \\
\text { iMRI (mm)* }\end{array}$ & $\begin{array}{c}\text { Dorsal CSF } \\
\text { Space, Supine } \\
\text { Preop MRI (mm)* }\end{array}$ & $\begin{array}{l}\text { Change in Dorsal CSF } \\
\text { Space, Prone iMRI }(\mathrm{mm})^{*}\end{array}$ & $\begin{array}{l}\text { Improvement in Cine } \\
\text { Flow After Positioning }\end{array}$ \\
\hline 1 & No & 1.1 & NA & 0.0 & NA & NA \\
\hline 2 & No & 1.7 & NA & 0.0 & NA & NA \\
\hline 3 & No & 1.5 & NA & 0.0 & NA & NA \\
\hline 4 & Yes & 2.0 & -1.0 & 2.0 & 0.0 & Yes \\
\hline 5 & Yes & 1.1 & -0.3 & 0.0 & 0.0 & Yes \\
\hline 6 & Yes & 2.6 & -1.6 & 0.0 & 1.0 & Yes \\
\hline 7 & Yes & 1.6 & -0.1 & 0.0 & 0.9 & Yes \\
\hline 8 & Yes & 0.7 & 0.2 & 0.0 & 2.1 & Yes \\
\hline 9 & Yes & 0.0 & 0.9 & 0.0 & 1.0 & Yes \\
\hline 10 & Yes & 0.9 & -0.2 & 2.0 & 0.2 & Yes \\
\hline 11 & Yes & 0.0 & 0.8 & 0.0 & 1.4 & Yes \\
\hline 12 & Yes & 0.0 & 1.0 & 0.0 & 1.0 & Yes \\
\hline 13 & Yes & 0.0 & 1.0 & 0.0 & 1.3 & Yes \\
\hline 14 & Yes & 4.2 & -3.7 & 0.0 & 1.0 & Yes \\
\hline 15 & Yes & 0.0 & 0.8 & 0.0 & 1.7 & Yes \\
\hline 16 & Yes & 4.0 & -0.3 & 0.0 & 2.0 & Yes \\
\hline 17 & Yes & 5.6 & -3.5 & 0.0 & 1.0 & No \\
\hline 18 & Yes & 1.0 & -0.3 & 1.0 & 0.0 & Yes \\
\hline Mean & & 1.6 & -0.4 & 0.3 & 1.0 & \\
\hline Median & & 1.1 & -0.2 & 0.0 & 1.0 & \\
\hline
\end{tabular}


malformation under this protocol, in 15 (83\%) preincision prone iMRIs were performed. The decision to perform a preincision iMRI was not made until after the first 2 patients had been studied, and the protocol was modified accordingly. In the third patient the prone iMRI was omitted because of a history of multiple prior surgeries and the plans for surgery with only removal of scar tissue. Table 2 summarizes the MRI findings in the supine and prone position. Fig. 1A-C shows the T2 sagittal images of a characteristic patient (Case A), as follows: preoperatively in the supine position (Fig. 1A), in the operating room prone with the neck flexed before the incision (Fig. 1B), and after bone decompression (Fig. 1C). The corresponding phasecontrast cine MRIs are shown in Fig. 1D-F, and the video sequence (Videos 1-3) can be viewed in the online version of this article.

VIDEO 1. Case A. Preoperative sagittal cine MRI in the supine position noting restricted dorsal CSF flow. Copyright Aaron Bond.

Published with permission. Click here to view with Windows Media Player. Click here to view with Quicktime.

VIDEO 2. Case A. Preincision sagittal cine iMRI with the patient in the prone position and the neck flexed noting significant improvement in dorsal CSF flow with positioning alone. Copyright Aaron Bond. Published with permission. Click here to view with Windows Media Player. Click here to view with Quicktime.

VIDEO 3. Case A. Sagittal cine iMRI obtained after bone decompression with the patient in the prone position and the neck flexed, noting good dorsal CSF flow but difficult to discern from the preincision MRI. Copyright Aaron Bond. Published with permission. Click here to view with Windows Media Player. Click here to view with Quicktime.

Findings in a second patient, Case B, are demonstrated in Fig. 2 and Videos 4-6.

VIDEO 4. Case B. Preoperative sagittal cine MRI in the supine position noting restricted dorsal CSF flow. Copyright Aaron Bond. Published with permission. Click here to view with Windows Media Player. Click here to view with Quicktime.

VIDEO 5. Case B. Preincision sagittal cine iMRI with the patient in the prone position and the neck flexed noting significant improvement in dorsal CSF flow with positioning alone. Copyright Aaron Bond. Published with permission. Click here to view with Windows Media Player. Click here to view with Quicktime.

VIDEO 6. Case B. Sagittal cine iMRI obtained after bone decompression with the patient in the prone position and the neck flexed noting good dorsal CSF flow but difficult to discern from the preincision MRI. Copyright Aaron Bond. Published with permission. Click here to view with Windows Media Player. Click here to view with Quicktime.

In both of these examples, by flexing the patient's neck to position it for surgery, the anatomical space and the flow in the dorsal CSF space enlarges significantly and no flow obstruction is detected before beginning any surgery. In our study, $93 \%$ of the patients demonstrated significantly improved dorsal CSF flow by the flexed positioning alone.

\section{Outcomes}

Eight of the 14 patients without prior surgery had the surgery terminated after the bone decompression alone, 4 after dural splitting, and 2 after duraplasty, based on the results of the iMRI. There was a mean follow-up time of 9.5 months. There was a single postoperative complica- tion of a corneal abrasion. Four patients with first-time surgeries underwent reoperation for persistence of symptoms. At the first surgery all 4 patients had received bone decompression only. Two other patients, 1 with bone decompression and 1 with dural splitting, had no resolution in symptoms but have not undergone additional surgery as this time. In summary, of the 14 first-time surgeries, 6 $(43 \%)$ clearly failed.

\section{Discussion}

The ideal operative strategy for treating the Chiari I malformation is the subject of debate. Gardner and Goodall, who convincingly demonstrated that the most common cause of syringomyelia is a Chiari I tonsillar malformation, described a series of 17 patients with syringomyelia in whom they opened the fourth ventricle and plugged the obex with muscle. ${ }^{5}$ In this way, they postulated that the "water hammer effect"- the pulsations transmitted from the fourth ventricle to the syrinx via a patent canal-would be eliminated. Later, Logue and Edwards described an alternative procedure that only included bone decompression and dural opening, avoiding opening of the arachnoid, and found similar results to those in Gardner and Goodall, but with significantly fewer complications. ${ }^{8}$ Currently the debate over the ideal surgical procedure revolves around performing a bone decompression alone, or proceeding with either a dural splitting procedure (opening the dura while leaving the arachnoid intact, with or without dural grafting), or opening the arachnoid for subarachnoid exploration. ${ }^{1,3,7,10,11,14}$ Some surgeons also include coagulation of the tonsils. ${ }^{4,12}$

Ideally there would exist an intraoperative tool that would enable the surgeon to assess whether adequate decompression has been obtained at each stage of the operation. In this way, the morbidity associated with opening the dura could be avoided in those patients who had adequate decompression without it. The most widely used intraoperative assessment during Chiari I decompression is intraoperative ultrasound, which is used to assess the fluid space between the dorsal aspect of the cerebellar tonsils and the dura, and it has been used to assess the decompression at various stages of the surgery. ${ }^{2,9,10,13,14}$ Others have monitored brainstem auditory evoked potentials during surgery for the same purpose. ${ }^{15}$ Yeh et al. used ultrasound as a metric to determine whether to proceed in 130 patients. ${ }^{14}$ Forty of their patients had normal ultrasound findings after bone decompression and the operations were terminated. Ninety patients had further duraplasty or tonsillectomy. When assessing the outcomes, $90 \%$ of the patients in the group with bone decompression alone had successful results, whereas $98 \%$ in the PFDD group had successful results. This implies that intraoperative ultrasound fails to completely identify patients who need further decompression, and in some patients it falsely predicts that surgery has been sufficient to provide good flow when, in fact, the flow was actually still compromised. As expected, in their study there was a significant difference in the number of patients with complications in the duraplasty group versus the group with bone decompression alone ( $14 \%$ vs $0 \%)$. 


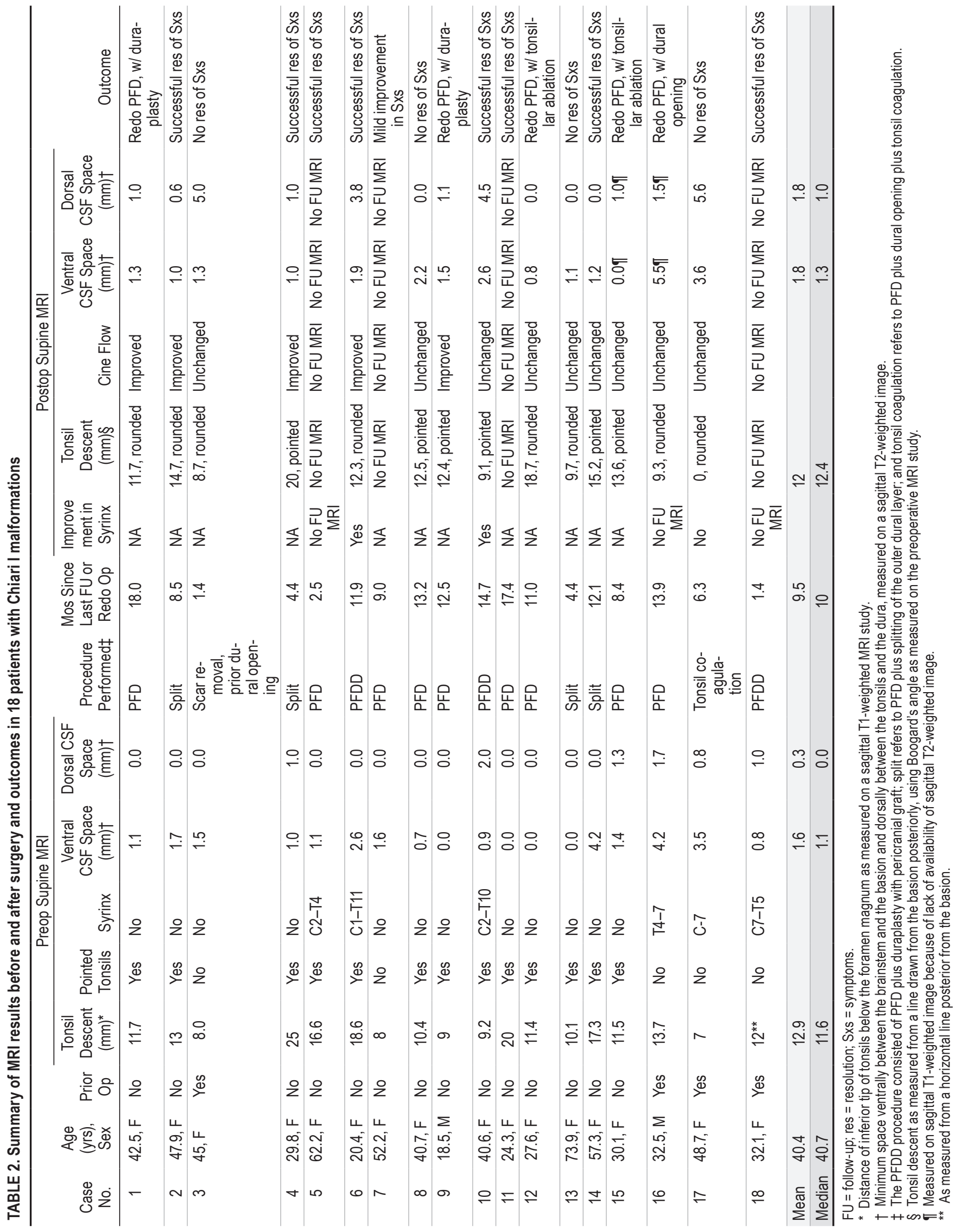




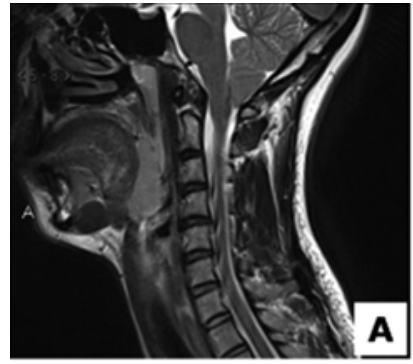

Pre-Op Supine

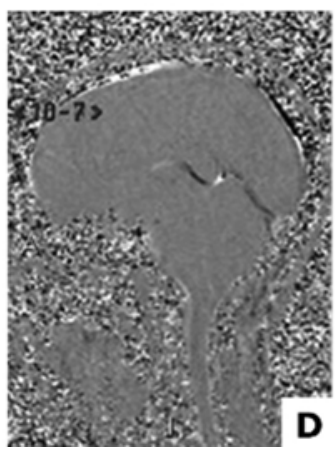

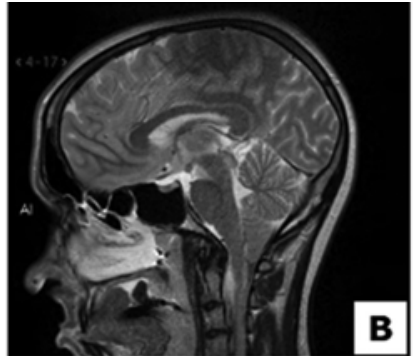

Prone Before Incision

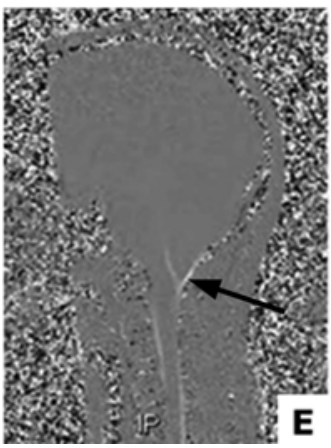

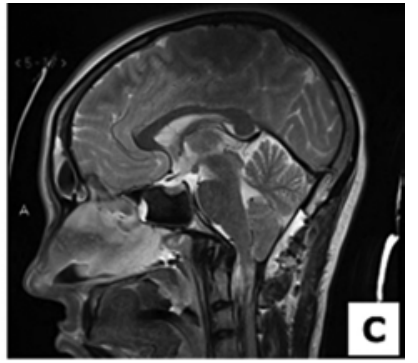

Prone Post Bone Removal

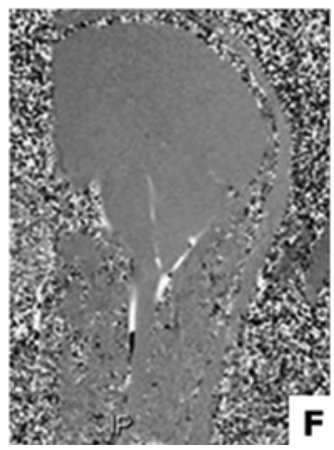

FIG. 1. Case A. Preoperative imaging (A), preincision in the prone surgical position with the neck flexed (B), and after bone decompression (C). The same patient's corresponding phase-contrast cine imaging studies are shown in panels $\mathbf{D}-\mathrm{F}$. The arrow points to the dorsal CSF space between the tonsils and the dura, and highlights the improvement in CSF flow. By flexing the neck in preparation for surgery, the space between the foramen magnum and the tonsils is significantly improved, limiting further assessment during the surgery.

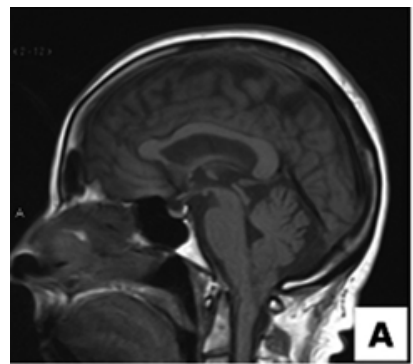

Pre-Op Supine

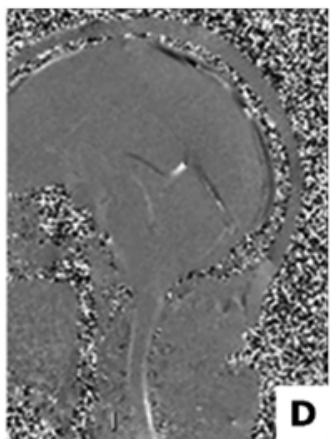

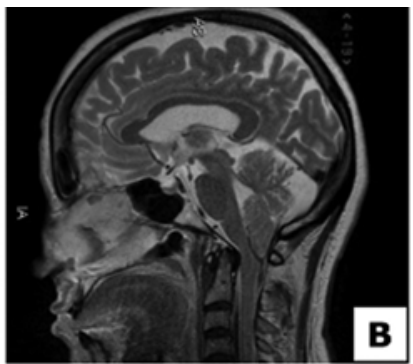

Prone Before Incision

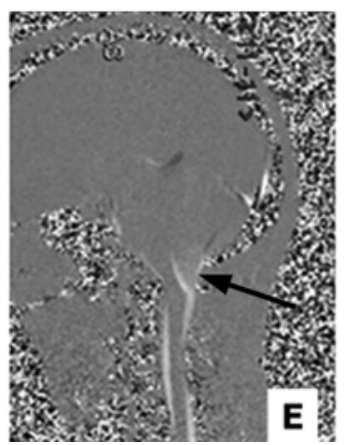

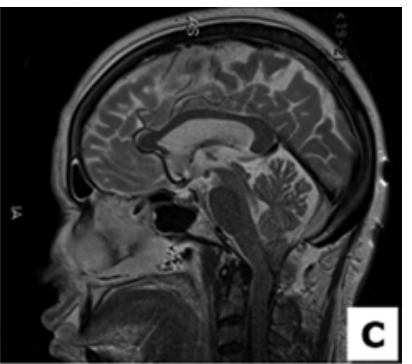

Prone Post Bone Removal

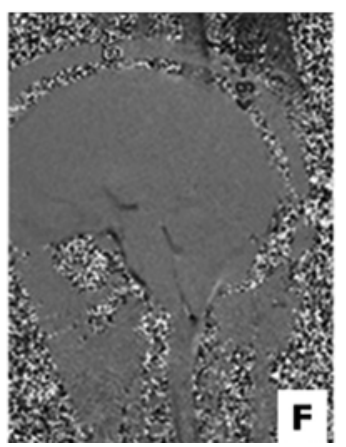

FIG. 2. Case B. Preoperative imaging (A), preincision in the prone surgical position with the neck flexed (B), and after bone decompression (C). The same patient's corresponding phase-contrast cine imaging studies are shown in panels D-F. The arrow points to the dorsal CSF space between the tonsils and the dura, and highlights the improvement in CSF flow. Similar results, with improvement in dorsal CSF flow, are observed in this patient. Ninety-five percent of patients had significant improvement in flow, with positioning limiting the utility of the intraoperative assessment. 
Intraoperative MRI provides the capacity to assess the CSF spaces beyond the bony margins. With the use of phase-contrast MRI the impact of decompression on the overall CSF flow can be assessed. When we began our study in which we used iMRI to assess patients with Chiari I malformation, we hoped to demonstrate that the modality could be used to better select patients who needed further decompression at various stages of the procedure. Our study immediately faced unexpected challenges related simply to positioning the patient.

When the patient is positioned for a Chiari I malformation decompression, it is common practice to flex the neck to approximately 1-2 fingerbreadths between the chin and chest. In this position, the surgeon has adequate access to the base of the skull to perform the craniectomy. After completing our first 2 cases in the iMRI suite we were surprised but pleased at the amount of improvement that was apparent in the CSF space and the flow on cine MRI after the bone decompression alone. The improvement was so significant that we questioned the effects of positioning. As a result, the remaining patients underwent a preincision prone iMRI study, which demonstrated the impact of the positioning alone. Fourteen of the 15 patients who had a preoperative prone iMRI performed (93\%) had significant improvement in the dorsal CSF flow by simply positioning the patient prone with neck flexion. In most patients the improvement after positioning alone was so prominent that further improvement after bone decompression was difficult to discern. The sagittal T2-weighted images obtained in the supine and prone position were assessed, and the dorsal CSF space between the tonsils and the dura had expanded by a mean of $1 \mathrm{~mm}$ from a mean supine value of $0.3 \mathrm{~mm}$, accounting for the improvement in cine MRI characteristics.

Our conclusions from this experience are that the impact of positioning on the results of iMRI is so profound that any intraoperative assessment tool currently in use is severely limited by this phenomenon, including the use of intraoperative ultrasound. We acknowledge that, since the surgeon assesses the cine iMRI and makes the decision to proceed based on a qualitative assessment of the CSF flow as visually reviewed on the cine image at surgery, the interpretation can include observer bias, although this observer bias is also present when using other intraoperative tools such as intraoperative ultrasound. We have suspended our protocol while we continue to consider solutions to this problem. We have considered the possibility of obtaining a supine image or an unflexed prone MR image after completing the decompression, but have not pursued it because of the additional time it would add to the procedure.

This paper is not meant to assess the outcomes of our patients who underwent surgery for Chiari I malformations with the use of iMRI, because the small number of patients and short follow-up precludes that. However, it should be noted that surgery in 6 patients has failed, and 4 patients have already undergone revision surgery even though the iMRI demonstrated adequate space and flow during surgery after bone decompression.

\section{Conclusions}

Placing patients in the prone position with the neck flexed compromises the accuracy of intraoperative imaging modalities, limiting their usefulness in PFDs for Chiari malformations.

\section{References}

1. Baisden J: Controversies in Chiari I malformations. Surg Neurol Int 3 (Suppl 3):S232-S237, 2012

2. Cui LG, Jiang L, Zhang HB, Liu B, Wang JR, Jia JW, et al: Monitoring of cerebrospinal fluid flow by intraoperative ultrasound in patients with Chiari I malformation. Clin Neurol Neurosurg 113:173-176, 2011

3. Durham SR, Fjeld-Olenec K: Comparison of posterior fossa decompression with and without duraplasty for the surgical treatment of Chiari malformation Type I in pediatric patients: a meta-analysis. J Neurosurg Pediatr 2:42-49, 2008

4. Galarza M, Gazzeri R, Alfieri A, Martínez-Lage JF: "Triple R" tonsillar technique for the management of adult Chiari I malformation: surgical note. Acta Neurochir (Wien) 155:1195-1201, 2013

5. Gardner WJ, Goodall RJ: The surgical treatment of ArnoldChiari malformation in adults; an explanation of its mechanism and importance of encephalography in diagnosis. J Neurosurg 7:199-206, 1950

6. Heiss JD, Patronas N, DeVroom HL, Shawker T, Ennis R, Kammerer W, et al: Elucidating the pathophysiology of syringomyelia. J Neurosurg 91:553-562, 1999

7. Isu T, Sasaki H, Takamura H, Kobayashi N: Foramen magnum decompression with removal of the outer layer of the dura as treatment for syringomyelia occurring with Chiari I malformation. Neurosurgery 33:845-850, 1993

8. Logue V, Edwards MR: Syringomyelia and its surgical treatment-an analysis of 75 patients. J Neurol Neurosurg Psychiatry 44:273-284, 1981

9. McGirt MJ, Attenello FJ, Datoo G, Gathinji M, Atiba A, Weingart JD, et al: Intraoperative ultrasonography as a guide to patient selection for duraplasty after suboccipital decompression in children with Chiari malformation Type I. J Neurosurg Pediatr 2:52-57, 2008

10. Milhorat TH, Bolognese PA: Tailored operative technique for Chiari type I malformation using intraoperative color Doppler ultrasonography. Neurosurgery 53:899-906, 2003

11. Mutchnick IS, Janjua RM, Moeller K, Moriarty TM: Decompression of Chiari malformation with and without duraplasty: morbidity versus recurrence. J Neurosurg Pediatr 5:474478, 2010

12. Nanda A: Principles of Posterior Fossa Surgery: Surgical Management. New York: Thieme, 2012

13. Oldfield EH, Muraszko K, Shawker TH, Patronas NJ: Pathophysiology of syringomyelia associated with Chiari I malformation of the cerebellar tonsils. Implications for diagnosis and treatment. J Neurosurg 80:3-15, 1994

14. Yeh DD, Koch B, Crone KR: Intraoperative ultrasonography used to determine the extent of surgery necessary during posterior fossa decompression in children with Chiari malformation Type I. J Neurosurg 105 (1 Suppl):26-32, 2006

15. Zamel K, Galloway G, Kosnik EJ, Raslan M, Adeli A: Intraoperative neurophysiologic monitoring in 80 patients with Chiari I malformation: role of duraplasty. J Clin Neurophysiol 26:70-75, 2009

\section{Author Contributions}

Conception and design: all authors. Acquisition of data: Bond. Analysis and interpretation of data: all authors. Drafting the article: Bond, Oldfield. Critically revising the article: all authors. Reviewed submitted version of manuscript: all authors. Approved 
the final version of the manuscript on behalf of all authors: Bond. Statistical analysis: Bond. Administrative/technical/material support: Jane, Liu, Oldfield. Study supervision: Jane, Oldfield.

\section{Videos}

Video 1, Media Player. http://mfile.akamai.com/21490/wmv/ digitalwbc.download .akamai.com/21492/wm.digitalsource-naregional/jns13-2712_video_1.asx.

Video 1, Quicktime. http://mfile.akamai.com/21488/mov/ digitalwbc.download.akamai.com/21492/qt.digitalsource-global/ jns13-2712_video_1.mov.

Video 2, Media Player. http://mfile.akamai.com/21490/wmv/ digitalwbc.download.akamai.com/21492/wm.digitalsource-naregional/jns13-2712_video_2.asx.

Video 2, Quicktime. http://mfile.akamai.com/21488/mov/ digitalwbc.download.akamai.com/21492/qt.digitalsource-global/ jns13-2712_video_2.mov.

Video 3, Media Player. http://mfile.akamai.com/21490/wmv/ digitalwbc.download.akamai.com/21492/wm.digitalsource-naregional/jns13-2712_video_3.asx.

Video 3, Quicktime. http://mfile.akamai.com/21488/mov/ digitalwbc.download.akamai.com/21492/qt.digitalsource-global/ jns13-2712_video_3.mov.
Video 4, Media Player. http://mfile.akamai.com/21490/wmv/ digitalwbc.download.akamai.com/21492/wm.digitalsource-naregional/jns13-2712_video_4.asx.

Video 4, Quicktime. http://mfile.akamai.com/21488/mov/ digitalwbc.download.akamai.com/21492/qt.digitalsource-global/ jns13-2712_video_4.mov.

Video 5, Media Player. http://mfile.akamai.com/21490/wmv/ digitalwbc.download.akamai.com/21492/wm.digitalsource-naregional/jns13-2712_video_5.asx.

Video 5, Quicktime. http://mfile.akamai.com/21488/mov/ digitalwbc.download.akamai.com/21492/qt.digitalsource-global/ jns13-2712_video_5.mov.

Video 6, Media Player. http://mfile.akamai.com/21490/wmv/ digitalwbc.download.akamai.com/21492/wm.digitalsource-naregional/jns13-2712_video_6.asx.

Video 6, Quicktime. http://mfile.akamai.com/21488/mov/ digitalwbc.download.akamai.com/21492/qt.digitalsource-global/ jns13-2712_video_6.mov.

\section{Correspondence}

Aaron E. Bond, Department of Neurosurgery, University of Virginia Health Science Center, Box 800212, Charlottesville, VA 22908. email: ab8nb@virginia.edu. 